\title{
Modulation of microglial activation enhances neuroprotection and functional recovery derived from bone marrow mononuclear cell transplantation after cortical ischemia
}

\author{
Edna C.S. Franco ${ }^{a}$, Marcelo M. Cardoso ${ }^{a}$, Amauri Gouvêia ${ }^{b}$, Antonio Pereirac ${ }^{c}$, Walace Gomes-Leal ${ }^{a, *}$ \\ a Laboratory of Experimental Neuroprotection and Neuroregeneration, Institute of Biological Sciences, Federal University of Pará, Brazil \\ ${ }^{\mathrm{b}}$ Laboratory of Neurosciences and Behavior, Institute of Biological Sciences, Federal University of Pará, Brazil \\ ${ }^{\mathrm{c}}$ Brain Institute, Federal University of Rio Grande do Norte, Natal, Brazil
}

\section{A R T I C L E I N F O}

\section{Article history:}

Received 8 September 2011

Received in revised form 24 February 2012

Accepted 13 March 2012

Available online 23 March 2012

\section{Keywords:}

Acute stroke

Stem cells

Microglia

Inflammation

Minocycline

Neuroprotection

\begin{abstract}
A B S T R A C T
Activated microglia may exacerbate damage in neural disorders; however, it is unknown how they affect stem cells transplanted after stroke. Focal ischemia was induced by microinjections of $40 \mathrm{pmol}$ of endothelin-1 into the motor cortex of adult rats. Ischemic animals were treated with sterile saline $(n=5)$, bone marrow mononuclear cells (BMMCs, $n=8)$, minocycline $(n=5)$ or concomitantly with minocycline and BMMCs $(n=5)$. BMMC-treated animals received $5 \times 10^{6}$ BMMCs through the caudal vein $24 \mathrm{~h}$ post-ischemia. Behavioral tests were performed to evaluate functional recovery. Morphometric and histological analyses were performed to assess infarct area, neuronal loss and microglia/macrophage activation up to 21 days post-ischemia. Treatments with minocycline, BMMCs or minocycline-BMMCs reduced infarct area, increased neuronal survival and decreased the number of caspase-3+ and ED-1+ cells, but these effects were more prominent in the minocycline-BMMC group. Behavioral analyses using the modified sticky-tape and open-field tests showed that ischemic rats concomitantly treated with BMMCs and minocycline showed better motor performance than rats treated with BMMCs or minocycline only. The results suggest that proper modulation of the inflammatory response through the blockage of microglia activation enhances neuroprotection and functional recovery induced by intravenous transplantation of BMMCs after motor cortex ischemia.
\end{abstract}

(c) 2012 Elsevier Ireland Ltd and the Japan Neuroscience Society. All rights reserved.

\section{Introduction}

Acute neural disorders, including stroke and brain and spinal cord trauma, are untreatable conditions and common causes of death or functional deficits (Zhang and Chopp, 2009). In central nervous system (CNS) diseases, several pathological events, such as excitotoxicity, free radical formation and inflammatory response, induce inexorable tissue damage and subsequent functional deficits (Woodruff et al., 2011).

Stroke, spinal cord injury (SCI) and other acute neural disorders are accompanied by an intense inflammatory response, characterized by cytokine release (Tuttolomondo et al., 2008), recruitment of neutrophils (Gomes-Leal et al., 2005; Schnell et al., 1999; SouzaRodrigues et al., 2008) and lymphocytes (Schroeter et al., 1994; Thored et al., 2009) and intense microglia activation (Gomes-Leal

\footnotetext{
* Corresponding author at: Laboratory of Experimental Neuroprotection and Neuroregeneration, Institute of Biological Sciences, Federal University of Pará, Rua Augusto Corrêa S/N, Campus do Guamá, CEP: 66075-900, Belém, Pará, Brazil. Tel.: +55 913201 7741; fax: +55 9132017741 .

E-mail addresses: leal@ufpa.br, wgomesleal@gmail.com (W. Gomes-Leal).
}

et al., 2004, 2005; Morioka et al., 1993; Thored et al., 2009) in the damaged CNS parenchyma.

Microglial activation is an important component of the CNS inflammatory response (Ransohoff and Perry, 2009). Several studies suggest that microglia may be protective after stroke and other CNS diseases (Lalancette-Hebert et al., 2007; Neumann et al., 2008; Thored et al., 2009) by modulating the inflammatory response through the release of anti-inflammatory cytokines (Battista et al., 2006) and growth factors (Lalancette-Hebert et al., 2007; Thored et al., 2009) and by engulfing neutrophils (Neumann et al., 2008) or increasing adult neurogenesis in vivo (Thored et al., 2009) and in vitro (Walton et al., 2006).

There is also substantial experimental evidence suggesting that an exacerbated microglial response may be detrimental after stroke and other CNS diseases (Block et al., 2007; Hamby et al., 2007; Yrjanheikki et al., 1999). Recently, it has been suggested that minocycline may be beneficial in acute ischemic stroke in humans (Lampl et al., 2007). Moreover, several studies corroborate the neuroprotective actions of minocycline in other CNS diseases (Yong et al., 2004), indicating that an uncontrolled microglial response is a common and important pathological event underlying several acute and chronic neural disorders (Block et al., 2007). 
Transplantation of stem cells is considered a promising therapeutic approach to minimize the burden of neurodegenerative diseases (Lindvall and Kokaia, 2006). Both embryonic (Takahashi et al., 2008) and adult stem cells (Brenneman et al., 2010; de Vasconcelos Dos Santos et al., 2010; Keimpema et al., 2009; Sarnowska et al., 2009) induce neuroprotective and functional recovery after stroke.

It has been shown that bone marrow mononuclear cells (BMMCs), a fraction of bone marrow containing both mesenchymal and hematopoietic stem cells (Weissman et al., 2001), are as effective as mesenchymal stem cells (MSCs) in inducing neuroprotection and locomotor recovery after experimental stroke (Brenneman et al., 2010; de Vasconcelos Dos Santos et al., 2010; Iihoshi et al., 2004). BMMC isolation does not involve long culturing procedures, which decreases the risk of contamination and renders these cells potentially suitable for transplantation a few hours after stroke onset (Brenneman et al., 2010; de Vasconcelos Dos Santos et al., 2010; Iihoshi et al., 2004), even in humans (Barbosa da Fonseca et al., 2010; Mendez-Otero et al., 2007).

In most of the studies available, stem cells were transplanted during the acute phase of stroke in an environment of intense inflammatory response (Brenneman et al., 2010; de Vasconcelos Dos Santos et al., 2010; Keimpema et al., 2009). This raises the possibility that transplanted cells could be harmed by the inflammatory environment, which includes activated microglia. This possibility is supported by reports suggesting that bone marrow stromal cells transplanted into the intact adult brain are rejected by an inflammatory response (Coyne et al., 2006) and that activated macrophages may impair both the survival and integration of embryonic stem cells transplanted at 3 days after brain trauma (Molcanyi et al., 2007).

It is unknown whether proper control of microglial activation in the ischemic environment could favor the therapeutic actions of transplanted stem cells. We explored whether the modulation of the inflammatory response by minocycline, an inhibitor of microglial activation, was beneficial for the therapeutic actions of BMMCs transplanted during the acute phase of cortical ischemia.

\section{Materials and methods}

\subsection{Experimental animals}

Male adult Wistar rats (250-300 g) were obtained from the Federal University of Pará Central Animal Facility. All animals were housed under standard conditions with food and water available ad libitum. All experimental procedures were carried out in accordance with the Principles of Laboratory Animal Care (NIH publication No. 86-23, revised 1985) and European Commission Directive 86/609/EEC for animal experiments under license of the Ethics Committee on Experimental Animals of the Federal University of Pará. All possible efforts were made to avoid animal suffering and distress.

\subsection{Surgical procedures and experimental model of focal ischemia}

The focal ischemia was induced by microinjections of the vasoconstrictor peptide endothelin-1 (ET-1) (Sigma, Saint Louis, MO, USA) as previously described by Souza-Rodrigues et al. (2008). Animals were anesthetized with ketamine hydrochloride $(72 \mathrm{mg} / \mathrm{kg}$, i.p.) and xylazine hydrochloride $(9 \mathrm{mg} / \mathrm{kg}$, i.p.) and held in a stereotaxic frame after their corneal reflex was abolished. A homoeothermic blanket unit was used to maintain the animal's body temperature, as measured by a rectal thermometer. After craniotomy, 40 pmol of ET-1 (Sigma, Saint Louis, MO, USA) in $1 \mu \mathrm{l}$ of sterile saline was injected into the rat motor cortex $(n=5-8$ per survival time/animal group) over a period of 2 min using a finely drawn glass capillary needle. The capillary needle was left in position for 3 min before being slowly withdrawn. Control animals were injected with the same volume of sterile saline ( $n=5$ per survival time). We used the following stereotaxic coordinates in relation to the bregma: $+2.3 \mathrm{~mm}$ lateral; $+1.2 \mathrm{~mm}$ posterior and $0.50 \mathrm{~mm}$ deep from the pial surface in the dorsoventral axis (Paxinos and Watson, 2007). To identify the injection site, a small quantity of colanyl blue was added to both ET-1 and vehicle solutions. After surgery, animals were allowed to recover with free access to food and water for 7,14 and 21 days.

\subsection{Animal groups}

To investigate whether microglial activation influences the effects of BMMCs transplanted during the acute phase following motor cortex ischemia, we delineated four experimental groups: animals injected with ET-1 and intravenously treated with sterile PBS (Group 1, $n=5$ ); animals injected with ET-1 and intravenously transplanted with BMMCs (Group 2, $n=8$ ); animals injected with ET-1 and treated (i.p.) with minocycline (Group 3, $n=5$ ) and animals injected with ET-1 and concomitantly treated with minocycline (i.p.) and intravenously transplanted with BMMCs (Group 4, $n=5$ ).

\subsection{Bone marrow harvesting and processing}

The harvesting of BMMCs followed the protocol described by Giraldi-Guimaraes et al. (2009). Briefly, rats were anesthetized with ketamine hydrochloride $(72 \mathrm{mg} / \mathrm{kg}$, i.p.) and xylazine hydrochloride $(9 \mathrm{mg} / \mathrm{kg}$, i.p.). The femoral and tibial bones were dissected, and their epiphyses were cut under sterile conditions in a laminar flow hood (VECO, CFLH-09). Bone marrow was extracted with serum-free DMEM-F12 (Sigma, Saint Louis, MO, USA) and gathered inside sterile tubes. Bone marrow cells were then mechanically dissociated and centrifuged for $5 \mathrm{~min}$ and resuspended in $3 \mathrm{ml}$ of serum-free DMEM-F12 (Sigma, Saint Louis, MO, USA). This volume was gently added over $3 \mathrm{ml}$ of Histopaque 1083 (Sigma, Saint Louis, MO, USA) and centrifuged for $30 \mathrm{~min}$. BMMCs were collected from the boundary between the DMEM-F12 (Sigma, Saint Louis, MO, USA) and the Histopaque 1083 (Sigma, USA). Cells were washed with Hanks solution without glucose in 3 consecutive series of centrifugation ( 5 min each). After washing, the cells were re-suspended in DMEM F12 (Sigma, Saint Louis, MO, USA), supplemented with $10 \%$ fetal calf serum (SBF) and counted using a Neubauer's chamber to a final concentration $5 \times 10^{6}$ cells $/ \mathrm{ml}$.

To label the transplanted BMMCs, bone marrow donor animals received daily injections ( $50 \mathrm{mg} / \mathrm{kg}$, i.p., twice a day for 7 days) of bromodeoxyuridine (BrdU, Sigma, Saint Louis, MO, USA). The exclusion test using trypan blue was performed to assess cell viability.

Twenty-four hours after ET-1-induced focal ischemia, Group 2 animals were intravenously transplanted with $5 \times 10^{6}$ BMMCs by tail vein injection ( $n=8 /$ survival time). In the control group, animals were injected with sterile PBS ( $n=5$ /survival time).

\subsection{Minocycline treatment}

Minocycline has been shown to be an effective inhibitor of microglial activation (Yrjanheikki et al., 1999). To inhibit microglial activation in the first week following cortical ischemia, animals (Group 3) received daily injections (twice a day) of minocycline (Sigma, Saint Louis, MO, $50 \mathrm{mg} / \mathrm{kg}$, i.p.) during the first two days. The first dose was administered $2 \mathrm{~h}$ after the ET- 1 microinjections. Subsequent doses of minocycline $(25 \mathrm{mg} / \mathrm{kg}$, i.p.) were administered once a day over the four subsequent days. The minocycline dose used is widely accepted as an effective dose in reducing microglia 
activation and inducing neuroprotection (Guimaraes et al., 2010; Hewlett and Corbett, 2006; Yrjanheikki et al., 1999). A separate group of animals was transplanted with BMMCs $24 \mathrm{~h}$ post-ischemia and concomitantly treated with minocycline for 6 days ( $n=5$, Group 4 ). These animals were killed at 7 days post-ischemia. This survival time was chosen because microglial activation is maximal in the first week following both ET-1-induced focal ischemia (SouzaRodrigues et al., 2008) and MCAO (Morioka et al., 1993).

\subsection{Analysis of sensorimotor dysfunction}

Sensorimotor outcome was assessed using behavioral tests performed by blinded investigators. Animals in all groups were tested one day before and 1, 3 and 7 days after ischemia. The following tests were used:

1. The open-field test (Bresnahan et al., 1987): This test was performed in an open field with $60 \mathrm{~cm} \times 60 \mathrm{~cm} \times 50 \mathrm{~cm}$ dimensions and containing 16 square subdivisions of equal size. Experiments consisted of three trials ( $5 \mathrm{~min}$ each) in which the animal was removed from its cage and placed at the center of the open field. The animals' motor performance was recorded by a video camera (Sony, USA). The behavioral parameters recorded included the number of occurrences of the exploratory behavior of standing up on the hind legs (rearing), body self-cleaning (grooming), latency (time taken to leave the starting point) and distance traveled in the open field.

2. The modified sticky-tape test: We used a protocol adapted from (Sughrue et al., 2006). A small non-removable tape sleeve $(3.0 \mathrm{~cm} \times 1.0 \mathrm{~cm})$ was placed around the animal's forepaw. The time spent attending to this stimulus was recorded. Animals were pre-trained $24 \mathrm{~h}$ before ischemia (two times a day for $30 \mathrm{~s}$ ) with a 1-h interval between each test. After ischemia, the test was performed once a day in the first, third and seventh days after ischemia. Each test consisted of five trials in which the two best performances were considered for quantitative analysis. The ratio of left to right performance was calculated to assess sensorimotor performance (Sughrue et al., 2006).

\subsection{Perfusion and tissue preparation}

After survival times of 7,14 and 21 days, animals were deeply anesthetized with ketamine hydrochloride $(72 \mathrm{mg} / \mathrm{kg}$, i.p.) and xylazine hydrochloride $(9 \mathrm{mg} / \mathrm{kg}$, i.p.) and transcardially perfused with heparinized $0.9 \%$ phosphate-buffered saline (PBS) followed by $4 \%$ paraformaldehyde. Surgical manipulation was performed only after both the corneal and the paw withdraw reflexes were abolished. Brains were post-fixed for $24 \mathrm{~h}$ in the same fixative and cryoprotected in different gradients of sucrose-glycerol solutions over 7 days. The tissue was then frozen in Tissue Tek, and 30$\mu \mathrm{m}$ coronal sections were cut using a cryostat (Carl Zeiss Micron, Germany). Sections were mounted onto gelatinized slides and stored in a freezer at $-20^{\circ} \mathrm{C}$.

\subsection{Gross histopathology}

The lesion area was visualized in sections stained with cresyl violet (Sigma, Brazil). The site of the ET- 1 injection was recognized by the presence of colanyl blue, tissue pallor and necrosis induced by focal ischemia (Souza-Rodrigues et al., 2008).

\subsection{Antibodies}

To evaluate the patterns of neuronal loss, microglial/ macrophage activation and apoptosis in the different experimental groups, we performed a series of immunohistochemical procedures. Table 1 shows details regarding the antibodies used for this purpose.

\subsection{Immunolabeling protocol}

The immunolabeling protocol used in this study was detailed elsewhere (Gomes-Leal et al., 2004). Briefly, slide-mounted sections were removed from the freezer, kept in a heating oven at $37^{\circ} \mathrm{C}$ for $30 \mathrm{~min}$ and rinsed once in $0.1 \mathrm{M}$ PBS for $5 \mathrm{~min}$. To improve labeling intensity, sections were then pretreated in $0.2 \mathrm{M}$ boric acid ( $\mathrm{pH}$ 9.0) previously heated to $65^{\circ} \mathrm{C}$ for $25 \mathrm{~min}$. This temperature was maintained constantly over the pretreatment period. Sections were further allowed to cool for about $20 \mathrm{~min}$ and were incubated under constant agitation in $1 \%$ hydrogen peroxide in methanol for $20 \mathrm{~min}$. Sections were rinsed 3 times ( $5 \mathrm{~min}$ each) in $0.05 \%$ PBS/Tween (Sigma, Saint Louis, MO, USA) and incubated with normal serum (Table 1) in PBS for $1 \mathrm{~h}$. Without further rinsing, sections were then incubated with the primary antibody diluted in PBS for $24 \mathrm{~h}$, rinsed in PBS/Tween solution for $5 \mathrm{~min}$ ( 3 times), and incubated with appropriate secondary antibody (Table 1 ) for $2 \mathrm{~h}$. Both primary and secondary antibodies were incubated at room temperature $\left(20^{\circ} \mathrm{C}\right)$. As a negative control, PBS, rather than the primary antibody, was used. Sections were rinsed again for $5 \mathrm{~min}$ (3 times) and incubated in an avidin-biotin-peroxidase complex ( $A B C$ Kit, Vector Laboratories) for $2 \mathrm{~h}$. Sections were then rinsed 4 times ( 3 min each rinse) and DAB-reacted according to a protocol published elsewhere (Gomes-Leal et al., 2004). After the DAB reaction, sections were rinsed 3 times ( 3 min each) in $0.1 \mathrm{M}$ phosphate buffer dehydrated using alcohols and xylene, and coverslipped. Some sections were also counterstained with cresyl violet.

\subsection{Qualitative analysis}

All sections stained with the different histological methods were surveyed by light microscopy (Olympus BX41). Illustrative images from all experimental groups were obtained using a digital camera (Olympus Evolt E-330) attached to the microscope.

\subsection{Quantitative analysis}

The measurement of the lesion area $\left(\mathrm{mm}^{2}\right)$ was performed using photomicrographs obtained from cresyl violet-stained sections for the different experimental groups (3 sections/animal/survival time) using the NIH's free software, Image J.

We used coronal sections containing the damaged motor cortex to count the number of activated microglia/macrophages (ED1-1+ cells), apoptotic cells (active caspase-3+ cells) and mature neuronal bodies (NeuN+ cells) per field using a square $0.25-\mathrm{mm}$-wide grid (objective $40 \times$ ) in the eyepiece of a microscope. In the $40 \times$ objective, this grid corresponds to an area of $0.0625 \mathrm{~mm}^{2}$. We counted 3 fields per section and 3 sections/animal ( $n=5$ animals/survival time). Fields were counted in the regions of highest cell density along a line from the lesion epicenter (central field) and in 2 additional fields at 1 -mm intervals ( $1 \mathrm{~mm}$ medially and $1 \mathrm{~mm}$ laterally). Counts were averaged and plotted in Cartesian coordinates. This protocol was adapted from (Schnell et al., 1999).

\subsection{Statistical analysis}

Averages and standard deviations were calculated for all counts. Comparisons between different groups were assessed by an analysis of variance (ANOVA) with Bonferroni post hoc test. Statistical significance was accepted for $P<0.05$. All statistical analyses were performed using the BioEstat 5.0 software (Sociedade Civil Mamiraua'/CNPQ-Brazil). 
Table 1

Antibodies and normal serum used.

\begin{tabular}{|c|c|c|c|}
\hline Primary antibodies & Secondary antibodies & Normal serum (10\%) & Labeling purpose \\
\hline Anti-BrdU (1:100, Novocastra) & $\begin{array}{l}\text { Horse anti-mouse ( } 1: 100 \\
\text { Vector Laboratories) }\end{array}$ & Horse & Transplanted cells (Li et al., 2001) \\
\hline Anti-active caspase-3 (1:250, Promega) & $\begin{array}{l}\text { Goat anti-rabbit ( } 1: 100 \\
\text { Vector Laboratories) }\end{array}$ & Goat & Apoptotic cells (Lalancette-Hebert et al., 2007) \\
\hline Anti-NeuN (1:100, Chemicon) & $\begin{array}{l}\text { Horse anti-mouse ( } 1: 100 \\
\text { Vector Laboratories) }\end{array}$ & Horse & Mature neurons (Mullen et al., 1992) \\
\hline Anti-ED-1 (1:200, Serotec) & $\begin{array}{l}\text { Horse anti-mouse ( } 1: 100 \\
\text { Vector Laboratories) }\end{array}$ & Horse & Activated microglia/macrophages (Robinson et al., 1986) \\
\hline
\end{tabular}

\section{Results}

\subsection{Visualization of transplanted BMMCs}

Transplanted BrdU+ BMMCs were present in different CNS regions, including the ischemic cortical parenchyma, meninges and perivascular space (Fig. 1). Few BMMCs were present in the perinfarct area, which is in agreement with previous studies showing that most of the transplanted cells are localized to non-neural organs (i.e., the spleen) and that most cells reaching the CNS has a transient existence (Brenneman et al., 2010; Keimpema et al., 2009).

\subsection{BMMC treatment decreases infarct area after cortical ischemia}

Microinjections of $40 \mathrm{pmol}$ of ET- 1 into the motor cortex of adult rats induced conspicuous tissue loss accompanied by an intense inflammatory reaction (Fig. 2), which is in agreement with previous studies using the ET-1 model of focal ischemia (Souza-Rodrigues et al., 2008). BMMC treatment decreased the tissue loss for all survival times (Fig. 2A-F), as confirmed by quantitative analysis
$(P<0.05$, ANOVA-Bonferroni) of the infarct area (Fig. 2G). The average infarct areas were $1.82( \pm 0.59), 1.97( \pm 0.12)$ and $1.79( \pm 0.32)$ $\mathrm{mm}^{2}$ at 7,14 and 21 days, respectively, in the vehicle group and 1.15 $( \pm 0.59), 0.80( \pm 0.18)$ and $0.82( \pm 0.31) \mathrm{mm}^{2}$ in the BMMC-treated animals (Fig. 2G).

\subsection{BMMC treatment reduces apoptosis and promotes neuronal preservation in the ischemic cortex}

ET-1 microinjections induced conspicuous loss of neuronal cell bodies (NeuN+ cells) for all survival times (Fig. 3). BMMC treatment increased neuronal preservation for all survival times (Fig. 3A-F) as confirmed $(P<0.01$, ANOVA-Bonferroni) by quantitative analysis (Fig. 3G). The average numbers of NeuN+ cells were $49( \pm 17), 35$ $( \pm 17)$ and $39( \pm 14)$ cells/field at 7, 14 and 21 days, respectively, in the vehicle group and $75( \pm 22), 62( \pm 22)$ and $77( \pm 28)$ cells/field in the BMMC-treated animals (Fig. 3G).

ET-1 microinjections increased the number of apoptotic cells (active caspase-3+ cells) mainly in the motor cortex perinfarct area (Fig. 4A-F). BMMC treatment reduced the number of these cells for all survival times, as confirmed $(P<0.05$, ANOVA-Bonferroni) by quantitative analysis (Fig. $4 \mathrm{H}$ ). The average numbers of active

\section{Ischemic Cortex}
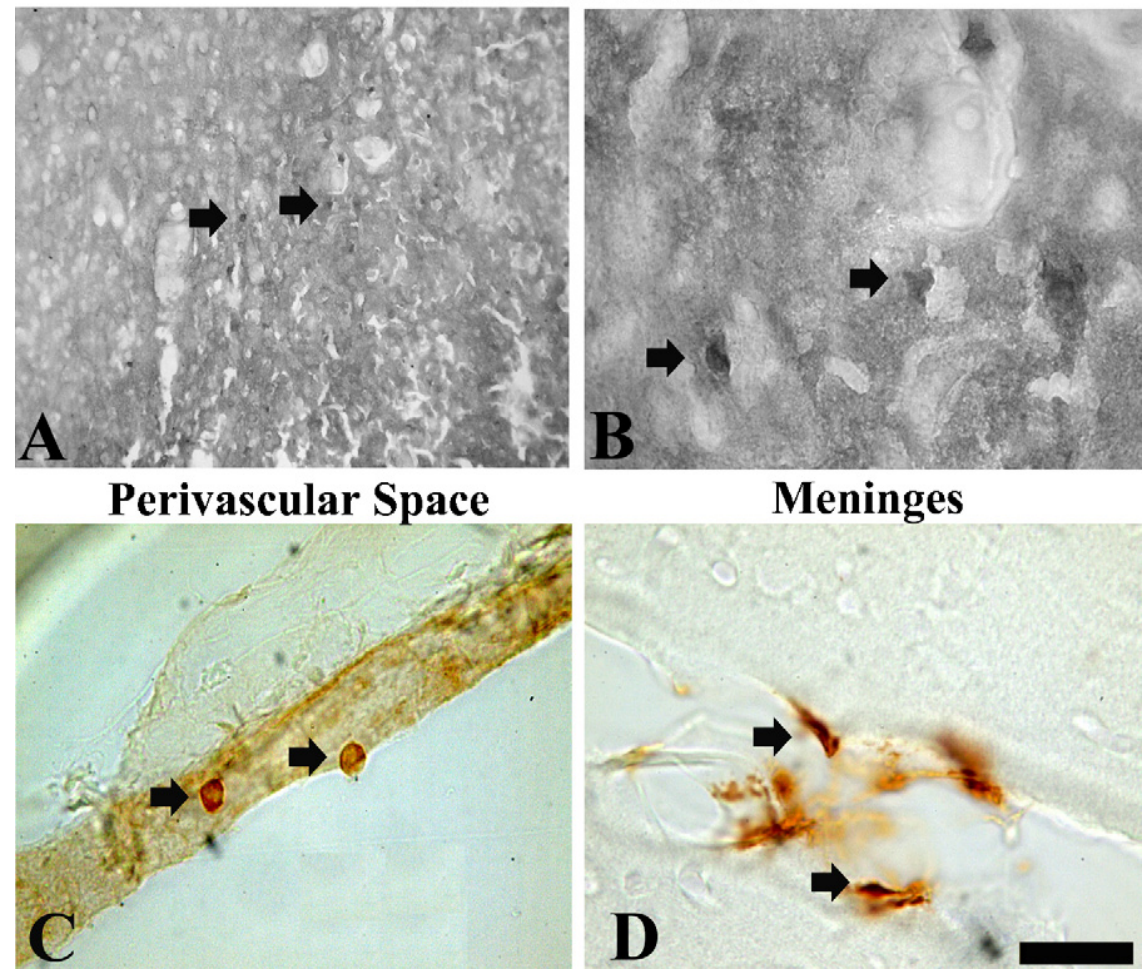

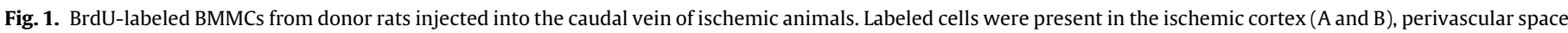
(C) and meninges (D). Arrows indicate BrdU-labeled BMMCs. Scale bar: $30 \mu \mathrm{m}$. 

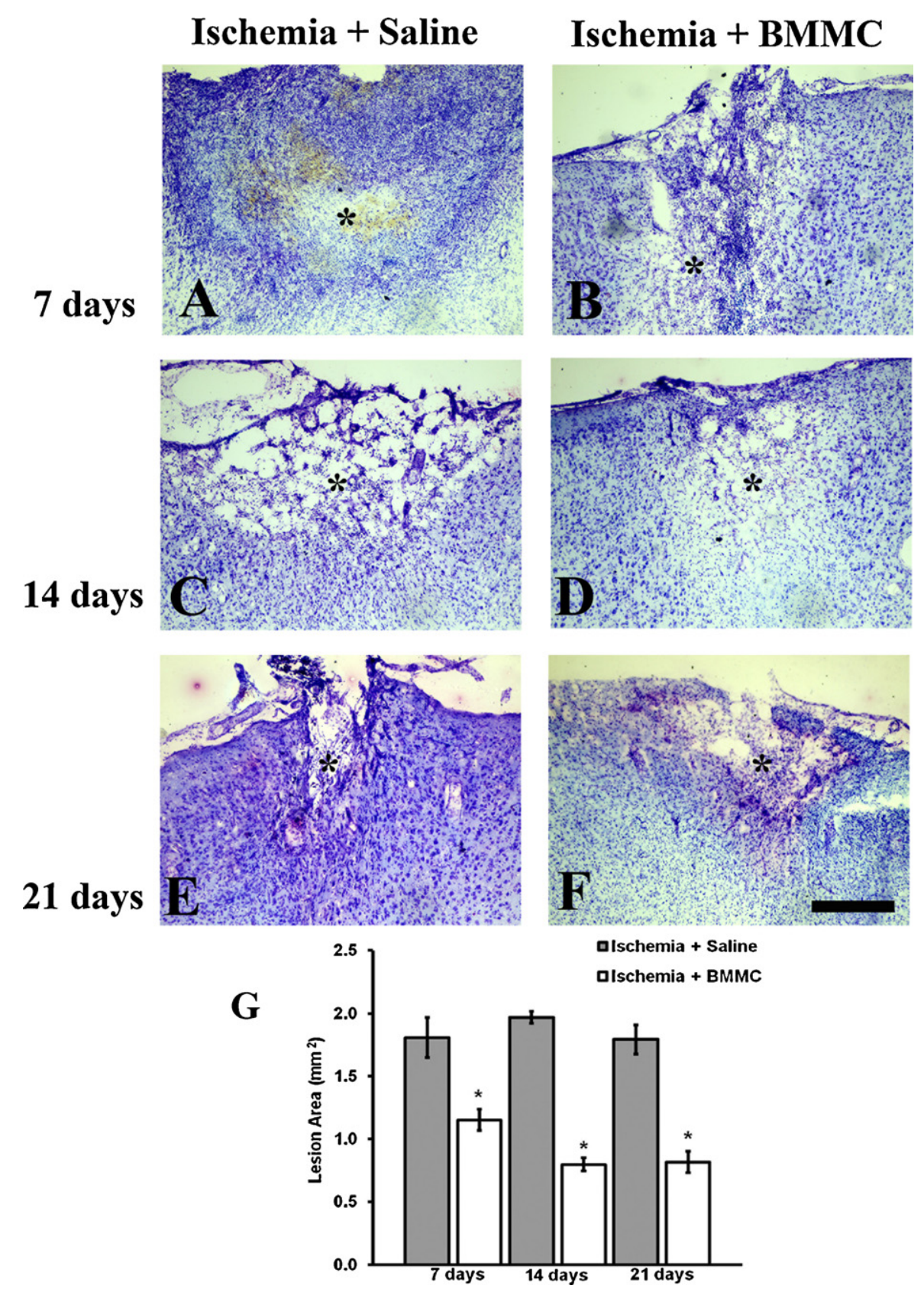

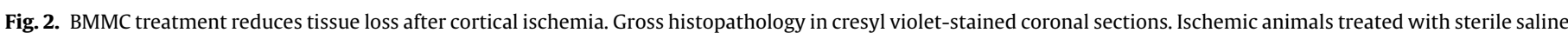

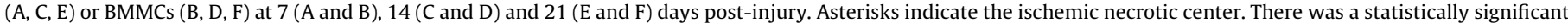
decrease in the infarct area after BMMC treatment for all survival times as compared to the vehicle control (G, ${ }^{*} P<0.05$ ANOVA-Bonferroni). Scale bar: $250 \mu \mathrm{m}$.

caspase-3+ cells were $38( \pm 11), 45( \pm 11)$ and $50( \pm 22)$ cells/field at 7,14 and 21 days, respectively, in the vehicle group and $30( \pm 11)$, $31( \pm 8)$ and $31( \pm 12)$ cells/field in BMMC-treated animals (Fig. $4 \mathrm{H})$.

\subsection{BMMC treatment reduces microglial/macrophage activation at a later survival time after cortical ischemia}

Microinjections of ET-1 induced an intense inflammatory response characterized by the presence of a large number of activated microglia/macrophages (ED1+ cells) in both the ischemic core and peripheral regions (Fig. 5A-F). The number of ED1+ cells was similar $(P>0.05$, ANOVA-Bonferroni) in both vehicle- and BMMC-treated animals at 7 ( $84 \pm 24$ and $81 \pm 18$ cells/field $)$ and 14 $(65 \pm 25$ and $64 \pm 28$ cells/field) days post-injury (Fig. 5G). However, there was a decrease $(P<0.05$, ANOVA-Bonferroni) in the number of ED1+ cells in BMMC-treated animals ( $63 \pm 25$ cells/field) as compared to the vehicle group ( $77 \pm 25$ cells/field) at 21 days post-injury (Fig. 5G).

\subsection{Inhibition of microglial activation improves BMMC-induced neuroprotection and functional recovery}

To test the hypothesis that the modulation of microglial activation in the ischemic environment might be beneficial for the therapeutic actions of BMMCs transplanted during the acute phase of cortical ischemia, microglial activation was inhibited using minocycline (Yrjanheikki et al., 1999). Minocycline treatment reduced the number of ED1+ cells in the motor cortex of ischemic animals at 7 days post-injury (Fig. 6C and M). Concomitant 


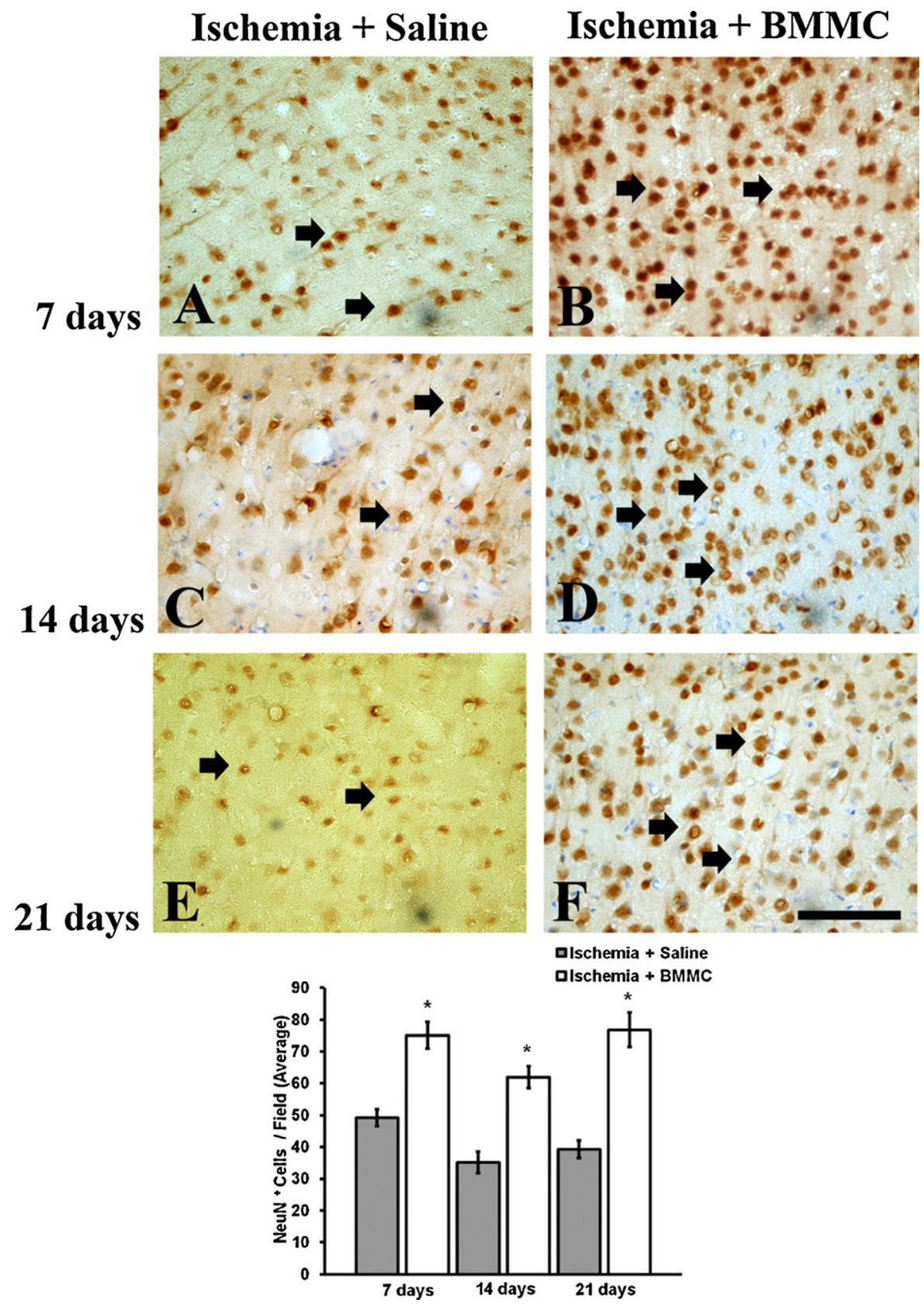

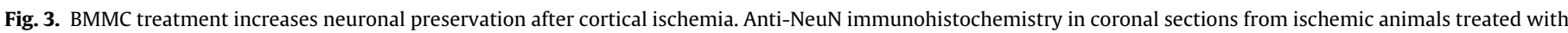

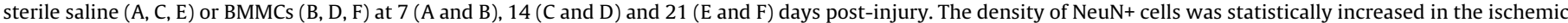
cortex after BMMC treatment for all survival times as compared to the vehicle control $\left(G,{ }^{*} P<0.05\right.$ ANOVA-Bonferroni $)$. Arrows indicate NeuN + cells. Scale bar: $100 \mu m$.

treatment with minocycline and BMMCs induced a greater decrease $(P<0.05)$ in the number of ED1+ cells (Fig. 6D and M).

Concomitant BMMC and minocycline treatment reduced infarct area compared to control animals, but not in comparison with minocycline or BMMC alone (not shown). Concomitant treatment reduced the number of apoptotic cells compared to control and BMMC treatment, but not in comparison to minocycline (Fig. 6I-L). Neuronal preservation was enhanced by concomitant treatment compared to control, but not in comparison to minocycline or BMMC treatment alone (Fig. 6E-H) at 7 days post-injury (Fig. 6E-H).

We investigated sensorimotor recovery in animals belonging to all experimental groups (Fig. 7). In a modified sticky-tape test, animals treated with BMMCs plus minocycline performed better at 7 days post-injury than animals treated with BMMCs or minocycline alone (Fig. 7A, $P<0.05$, ANOVA-Bonferroni,). In the open-field test, animals treated with BMMCs plus minocycline performed better in all analyzed parameters (i.e., mean distance traveled, rearing, grooming and latency time) than vehicle-treated animals (Fig. 7B-E, $P<0.05$, ANOVA-Bonferroni).

\section{Discussion}

We tested the hypothesis that microglial activation is detrimental to BMMCs transplanted during the acute phase (24h) of cortical ischemia and that inhibition of microglial activation with minocycline might facilitate the therapeutic effects of BMMCs in the ischemic environment.

The present data show that BMMC treatment induces a considerable reduction of the infarct area and apoptosis and increases neuronal preservation and functional recovery at 7, 14 and 21 days after cortical ischemia. In addition, we show that transplantation of BMMCs concomitant with minocycline treatment in the first 

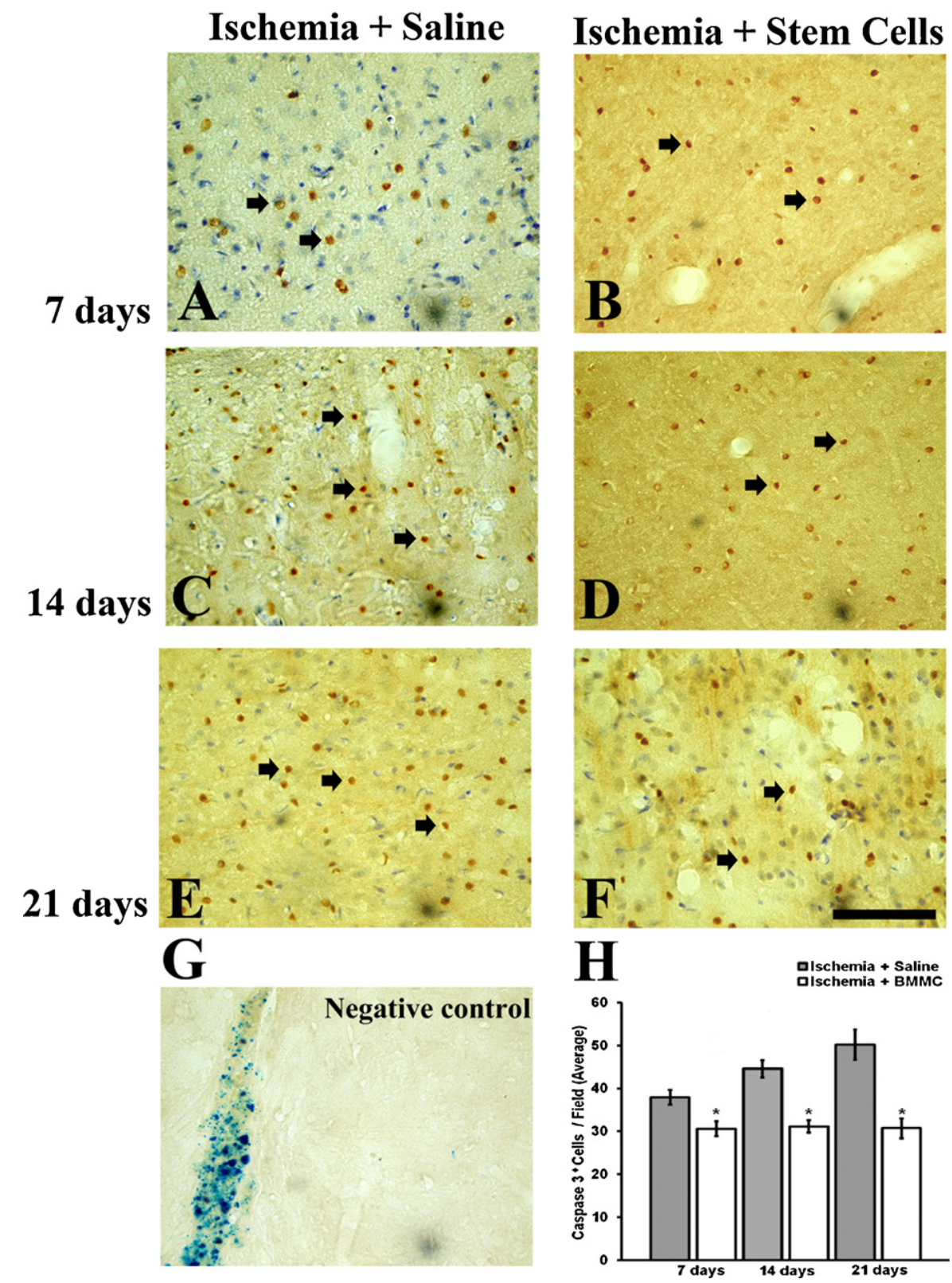

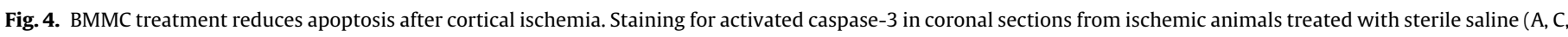

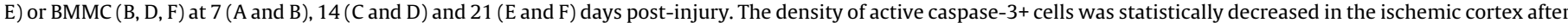

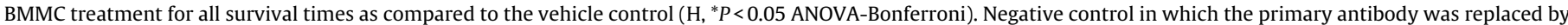
normal serum $(G)$. Sections in A, C and F were counterstained with cresyl violet. Arrows indicate active caspase- $3+$ cells. Scale bar: $100 \mu m$.

week after cortical ischemia improves the neuroprotection and functional recovery afforded by treatment with BMMCs alone.

These results confirm and extend previous reports suggesting that bone marrow-derived stem cells are highly neuroprotective following CNS disorders, including stroke (Bao et al., 2011; Brenneman et al., 2010; de Vasconcelos Dos Santos et al., 2010; Keimpema et al., 2009) and spinal cord trauma (Sobani et al., 2010). In these studies, isolated MSCs (Bao et al., 2011; Keimpema et al., 2009) or BMMCs (Brenneman et al., 2010; de Vasconcelos Dos Santos et al., 2010) were used for transplantation.

After intravenous transplantation, BMMCs (BrdU+) were present in several CNS regions, including the cortical perinfarct area, meninges and perivascular space, which is in agreement with previous reports (Brenneman et al., 2010; Chopp et al., 2009; Keimpema et al., 2009). Few BMMCs were present in the ischemic cortex mostly in the perinfarct area, which is also in agreement with previous studies (Chopp et al., 2009; Keimpema et al., 2009). It has been shown that these cells are preferentially found in non-neural tissues (i.e., the spleen) and have an early and transient existence in the ischemic environment (Keimpema et al., 2009). Keimpema et al. (2009) showed that after MCAO, around 95\% of transplanted BMMCs are trapped in the spleen shortly after arterial injection and they arrive in the ischemic cortex between 6 and $12 \mathrm{~h}$ after MCAO. Similar findings have been obtained using the intravenous route (Yang et al., 2011). The migration of these cells towards the lesion site seems to involve the release of stroma-derived factor- $1 \alpha$ (SDF-1 $\alpha$ ) by astrocytes, neurons and endothelial cells as well as the expression of the SDF- $1 \alpha$ receptor by MSCs (Chopp et al., 2009).

Despite their low numbers and transient existence, several studies have shown that bone marrow-derived cells are highly neuroprotective after experimental stroke (Bao et al., 2011; Brenneman et al., 2010; de Vasconcelos Dos Santos et al., 2010; 


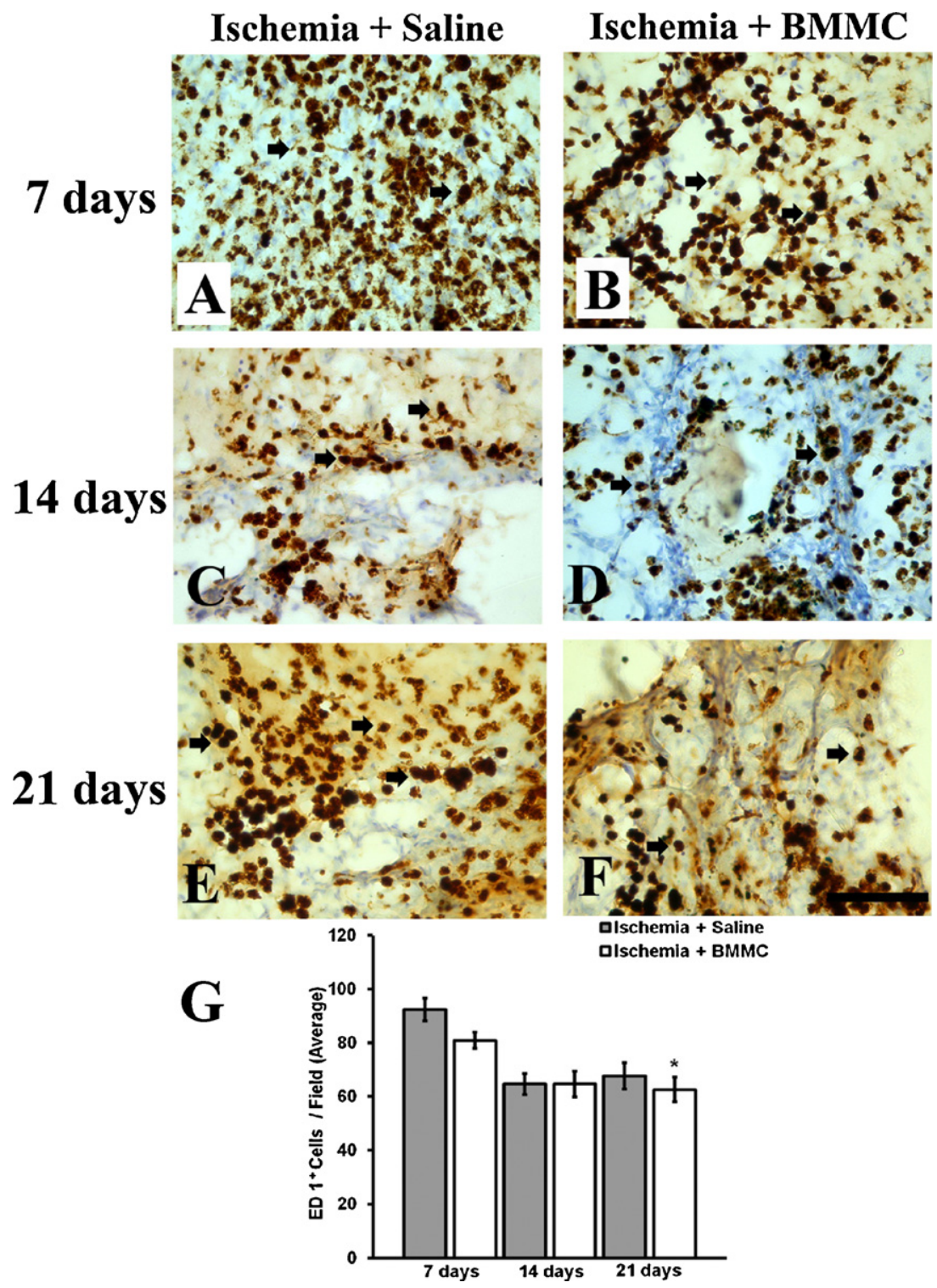

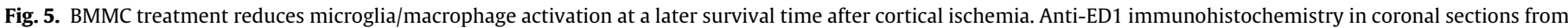

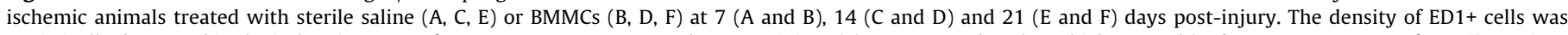

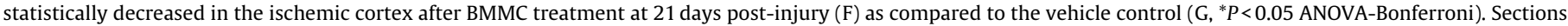
were counterstained with cresyl violet. Arrows indicate ED1+ cells. Scale bar: $100 \mu \mathrm{m}$.

Keimpema et al., 2009). However, most of these studies evaluated only a few histopathological parameters (mainly the infarct area), and apoptosis and neuronal density were not commonly assessed (Brenneman et al., 2010; de Vasconcelos Dos Santos et al., 2010; Keimpema et al., 2009; Schwarting et al., 2008).

In this study, intravenous transplantation of BMMCs at $24 \mathrm{~h}$ post-ischemia decreased the infarct area and apoptosis and increased neuronal density up to 21 days post-ischemia. Sensorimotor performance was also higher in BMMC-treated animals during this period. These results suggest a long-lasting protective effect of BMMCs after cortical ischemia. Although the mechanisms underlying the BMMC-derived protective actions are not fully understood, they probably do not involve transdifferentiation with cell replacement. Rather, they likely involve the modulation of the ischemic environment by release of growth factors and antiinflammatory cytokines (Chopp et al., 2009; Sarnowska et al., 2009; Schwarting et al., 2008).

Several soluble factors are directly released by bone marrowderived cells, including fibroblast growth factor-1 (FGF-2), epidermal growth factor (EGF), brain-derived neurotrophic factor (BDNF), nerve growth factor (NGF), vascular endothelial growth factor (VEGF), brain natriuretic peptide (BNP), erythropoietin and anti-inflammatory cytokines (Chopp et al., 2009; Sarnowska et al., 2009). Moreover, BMSCs can modulate the activity of both astrocytes and microglia, inducing these cells to release growth factors and/or anti-inflammatory cytokines (Chopp et al., 2009; Sarnowska et al., 2009). In addition, it has been shown that MSCs may exert therapeutic effects by enhancing endogenous neurogenesis and protecting newly born cells after MCAO (Yoo et al., 2008). In the present study, BMMCs might have released such soluble factors to contribute to apoptosis reduction and neuronal preservation. This is in agreement with a recent study showing that BMSCs may release NGF, FGF and IGF in hippocampal organotypic slice cultures (Sarnowska et al., 2009). According to these authors, diffuse neurotrophic factors can provide neuroprotection without the necessity of cell-cell contact. These findings can explain how a low number of BMMCs may induce significant neuroprotection in the ischemic parenchyma. It has been shown that most BMMCs 

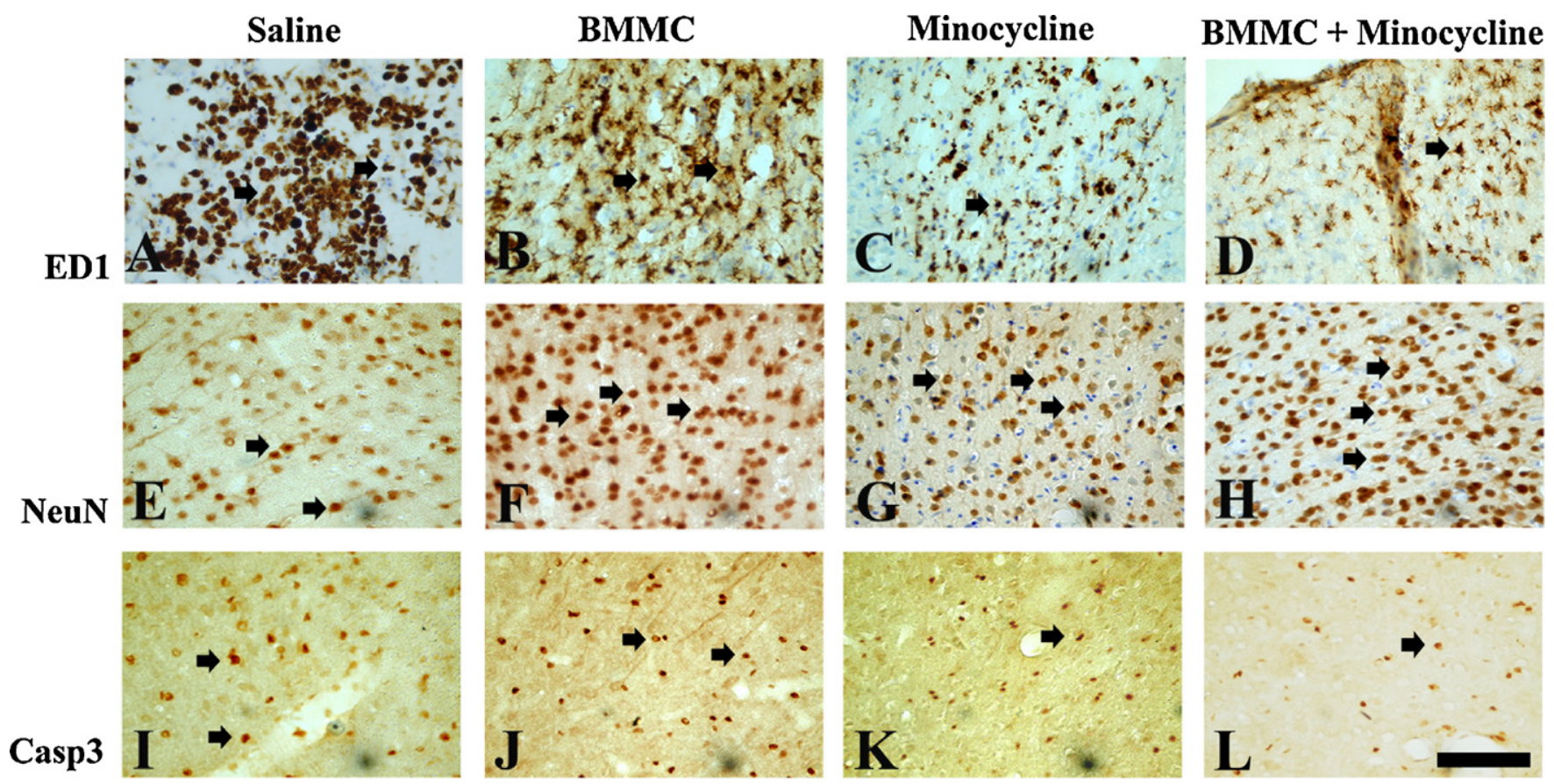

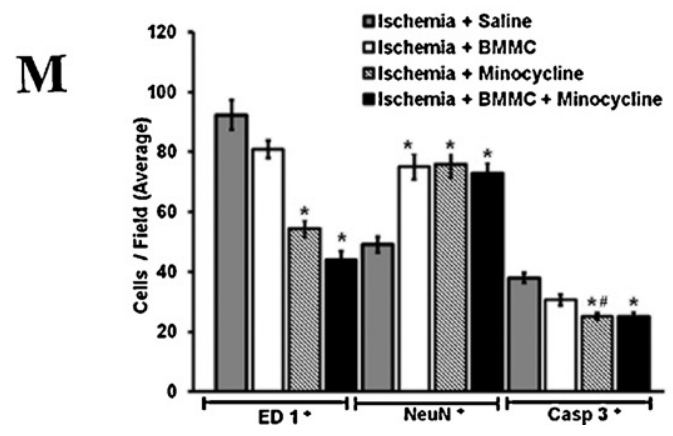

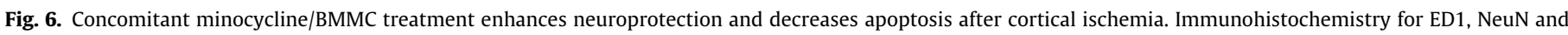

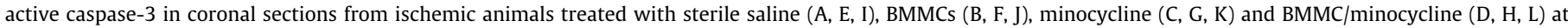

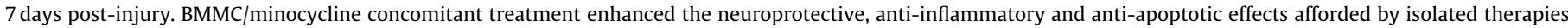

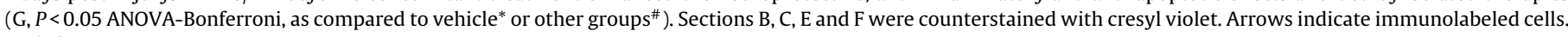
Scale bar: $100 \mu \mathrm{m}$.

die shortly after entering the ischemic tissue, but they modulate the ischemic environment even during their transient existence (Keimpema et al., 2009).

The main goal of this study was to investigate whether modulation of microglial activation would facilitate the therapeutic effects of BMMCs in the ischemic environment. Minocycline treatment reduced the number of ED1+ cells in the first week after cortical ischemia and clearly improved the neuroprotection and functional recovery afforded by treatment of ischemic animals with BMMCs only. These results suggest that exacerbated microglia activation impairs BMMC actions in the ischemic environment and that microglia modulation with minocycline creates a more permissive environment for the transplanted BMMCs. It is well established that overactivated microglia are detrimental following focal ischemia and that the microglial inhibitor, minocycline, reduces infarct area and contributes to functional recovery after stroke (Lampl et al., 2007; Yrjanheikki et al., 1999). Nevertheless, no previous studies investigated whether activated microglia influence transplanted stem cells in the ischemic environment. The present results are supported by reports showing that bone marrow stromal cells transplanted into the intact adult brain are rejected by an inflammatory response (Coyne et al., 2006) and that activated macrophages impair survival and integration of embryonic stem cells transplanted 3 days after brain trauma (Molcanyi et al., 2007). In addition, a recent paper has shown that minocycline treatment increases the survival of porcine fetal neurons intrastriatally transplanted into the rat brain (MichelMonigadon et al., 2010). In this study, inhibition of microglia activation and lymphocyte infiltration in a later survival time was clearly associated with survival of transplanted stem cells (Michel-Monigadon et al., 2010).

We investigated sensorimotor recovery in animals belonging to all experimental groups. Animals treated with BMMC plus minocycline animals showed better performance in all behavioral tests administered mainly at 7 days post-injury. The results suggest that concomitant treatment using minocycline and BMMCs enhances the effect of BMMCs on functional recovery after cortical ischemia. Other studies have shown that treatment with isolated MSCs (Bao et al., 2011; Schwarting et al., 2008) or BMMCs (Brenneman et al., 2010; de Vasconcelos Dos Santos et al., 2010) improves sensorimotor recovery after stroke. Histological preservation induced by the transplanted BMSCs through the mechanisms discussed above likely underlies the behavioral improvement shown in these studies. Inhibition of microglia likely improves these effects by creating 

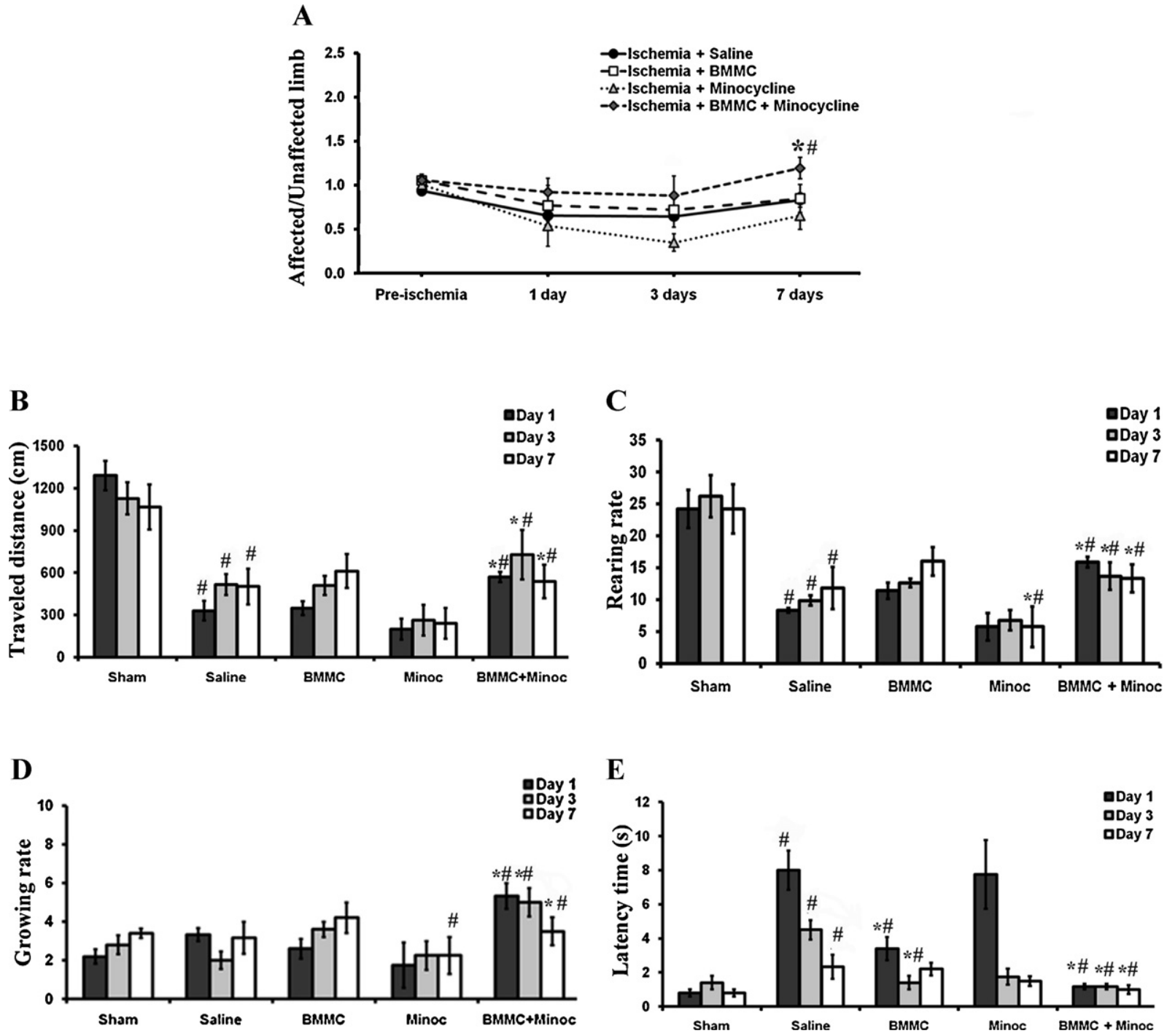

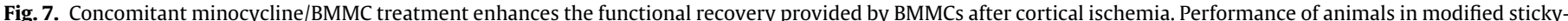

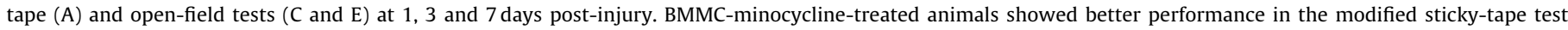

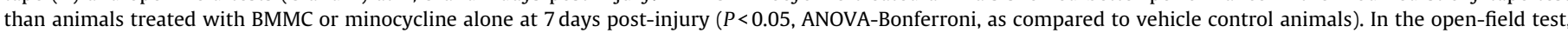

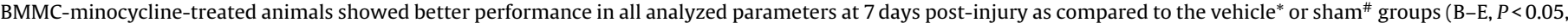
ANOVA-Bonferroni).

a more permissive environment for neural repair (Keimpema et al., 2009; Lalancette-Hebert et al., 2007; Schwarting et al., 2008).

Although the data suggest a deleterious effect of activated microglia on therapeutic actions of BMMCs, there are reports suggesting that BMSCs may exert neuroprotective actions by changing the ischemic environment through interactions with microglia (Keimpema et al., 2009; Schwarting et al., 2008). The phenotype of these glial cells is likely modulated by anti-inflammatory cytokines and growth factors released by BMSCs, rendering them beneficial after ischemia (Keimpema et al., 2009; Schwarting et al., 2008). It has been shown that microglia may provide benefits after ischemia by releasing IGF-1 and anti-inflammatory cytokines (LalancetteHebert et al., 2007; Thored et al., 2009). It follows that a complete inhibition of microglial activation is not an ideal approach; rather, modulation of microglial activity may be a better solution. The experimental data available suggest that minocycline does modulate microglial activity. It is possible that minocycline inhibits the activation of deleterious populations of microglia without affecting the beneficial ones. This should be investigated in further studies using double immunofluorescence with specific phenotypic markers for microglia. Moreover, minocycline has other pleiotropic effects beyond microglia inhibition (Yong et al., 2004), which can be also partially responsible for its neuroprotective effects.

\section{Conclusion}

Our data support the notion that uncontrolled microglial activation is detrimental to the therapeutic actions of BMMCs transplanted during the acute phase of cortical ischemia. A proper modulation of the microglial response in the ischemic environment provides better neuroprotection and functional recovery than the transplantation of BMMCs only. This anti-inflammatory approach may represent an important adjuvant therapy to improve therapeutic actions of stem cells transplanted during the acute phase of CNS diseases.

\section{Conflict of interest statement}

The authors declare no conflict of interest. 


\section{Acknowledgements}

This work was supported by the Brazilian National Council for Scientific and Technological Development (CNPq) and Fundação de Amparo A Pesquisa do Estado do Pará (FAPESPA). W Gomes-Leal is a principal investigator in grant number 573872/2008-2 from the Ministry of Science and Technology (MCT), Ministry of Health (MS) and CNPq (Edital CT-Biotecnologia/MCT/CNPq/MS/SCTIE/DECIT no. 17/2008) and FAPESPA (PRONEX-FAPESPA-CNPQ-Edital 0122009).

\section{References}

Bao, X., Wei, J., Feng, M., Lu, S., Li, G., Dou, W., Ma, W., Ma, S., An, Y., Qin, C., Zhao, R.C., Wang, R., 2011. Transplantation of human bone marrow-derived mesenchymal stem cells promotes behavioral recovery and endogenous neurogenesis after cerebral ischemia in rats. Brain Res. 1367, 103-113.

Barbosa da Fonseca, L.M., Gutfilen, B., Rosado de Castro, P.H., Battistella, V., Goldenberg, R.C., Kasai-Brunswick, T., Chagas, C.L., Wajnberg, E., Maiolino, A., Salles Xavier, S., Andre, C., Mendez-Otero, R., de Freitas, G.R., 2010. Migration and homing of bone-marrow mononuclear cells in chronic ischemic stroke after intra-arterial injection. Exp. Neurol. 221, 122-128.

Battista, D., Ferrari, C.C., Gage, F.H., Pitossi, F., 2006. Neurogenic niche modulation by activated microglia: transforming growth factor beta increases neurogenesis in the adult dentate gyrus. Eur. J. Neurosci. 23, 83-93.

Block, M.L., Zecca, L., Hong, J.S., 2007. Microglia-mediated neurotoxicity: uncovering the molecular mechanisms. Nat. Rev. Neurosci. 8, 57-69.

Brenneman, M., Sharma, S., Harting, M., Strong, R., Cox Jr., C.S., Aronowski, J., Grotta, J.C., Savitz, S.I., 2010. Autologous bone marrow mononuclear cells enhance recovery after acute ischemic stroke in young and middle-aged rats. J. Cereb. Blood Flow Metab. 30, 140-149.

Bresnahan, J.C., Beattie, M.S., Todd, F.D., Noyes 3rd, D.H., 1987. A behavioral and anatomical analysis of spinal cord injury produced by a feedback-controlled impaction device. Exp Neurol 95, 548-570.

Chopp, M., Li, Y., Zhang, Z.G., 2009. Mechanisms underlying improved recovery of neurological function after stroke in the rodent after treatment with neurorestorative cell-based therapies. Stroke 40, S143-S145.

Coyne, T.M., Marcus, A.J., Woodbury, D., Black, I.B., 2006. Marrow stromal cells transplanted to the adult brain are rejected by an inflammatory response and transfer donor labels to host neurons and glia. Stem Cells 24, 2483-2492.

de Vasconcelos Dos Santos, A., da Costa Reis, J., Diaz Paredes, B., Moraes, L., Jasmin Giraldi-Guimaraes, A., Mendez-Otero, R., 2010. Therapeutic window for treatment of cortical ischemia with bone marrow-derived cells in rats. Brain Res. 1306, 149-158.

Giraldi-Guimaraes, A., Rezende-Lima, M., Bruno, F.P., Mendez-Otero, R., 2009. Treatment with bone marrow mononuclear cells induces functional recovery and decreases neurodegeneration after sensorimotor cortical ischemia in rats. Brain Res. 9, 108-120.

Gomes-Leal, W., Corkill, D.J., Freire, M.A., Picanco-Diniz, C.W., Perry, V.H., 2004. Astrocytosis, microglia activation, oligodendrocyte degeneration, and pyknosis following acute spinal cord injury. Exp. Neurol. 190, 456-467.

Gomes-Leal, W., Corkill, D.J., Picanco-Diniz, C.W., 2005. Systematic analysis of axonal damage and inflammatory response in different white matter tracts of acutely injured rat spinal cord. Brain Res. 1066, 57-70.

Guimaraes, J.S., Freire, M.A., Lima, R.R., Picanco-Diniz, C.W., Pereira, A., Gomes-Leal, W., 2010. Minocycline treatment reduces white matter damage after excitotoxic striatal injury. Brain Res.

Hamby, A.M., Suh, S.W., Kauppinen, T.M., Swanson, R.A., 2007. Use of a poly(ADPribose) polymerase inhibitor to suppress inflammation and neuronal death after cerebral ischemia-reperfusion. Stroke 38, 632-636.

Hewlett, K.A., Corbett, D., 2006. Delayed minocycline treatment reduces long-term functional deficits and histological injury in a rodent model of focal ischemia. Neuroscience 141, 27-33.

Iihoshi, S., Honmou, O., Houkin, K., Hashi, K., Kocsis, J.D., 2004. A therapeutic window for intravenous administration of autologous bone marrow after cerebral ischemia in adult rats. Brain Res. 1007, 1-9.

Keimpema, E., Fokkens, M.R., Nagy, Z., Agoston, V., Luiten, P.G., Nyakas, C., Boddeke, H.W., Copray, J.C., 2009. Early transient presence of implanted bone marrow stem cells reduces lesion size after cerebral ischaemia in adult rats. Neuropathol. Appl. Neurobiol. 35, 89-102.

Lalancette-Hebert, M., Gowing, G., Simard, A., Weng, Y.C., Kriz, J., 2007. Selective ablation of proliferating microglial cells exacerbates ischemic injury in the brain. J. Neurosci. 27, 2596-2605

Lampl, Y., Boaz, M., Gilad, R., Lorberboym, M., Dabby, R., Rapoport, A., AncaHershkowitz, M., Sadeh, M., 2007. Minocycline treatment in acute stroke: an open-label, evaluator-blinded study. Neurology 69, 1404-1410.

Li, Y., Chen, J., Chopp, M., 2001. Adult bone marrow transplantation after stroke in adult rats. Cell Transplant 10, 31-40.

Lindvall, O., Kokaia, Z., 2006. Stem cells for the treatment of neurological disorders. Nature 441, 1094-1096.
Mendez-Otero, R., de Freitas, G.R., Andre, C., de Mendonca, M.L., Friedrich, M. Oliveira-Filho, J., 2007. Potential roles of bone marrow stem cells in stroke therapy. Regen. Med. 2, 417-423.

Michel-Monigadon, D., Nerriere-Daguin, V., Leveque, X., Plat, M., Venturi, E., Brachet, P., Naveilhan, P., Neveu, I., 2010. Minocycline promotes long-term survival of neuronal transplant in the brain by inhibiting late microglial activation and $\mathrm{T}$ cell recruitment. Transplantation $89,816-823$.

Molcanyi, M., Riess, P., Bentz, K., Maegele, M., Hescheler, J., Schafke, B., Trapp, T. Neugebauer, E., Klug, N., Schafer, U., 2007. Trauma-associated inflammatory response impairs embryonic stem cell survival and integration after implantation into injured rat brain. J. Neurotrauma 24, 625-637.

Morioka, T., Kalehua, A.N., Streit, W.J., 1993. Characterization of microglial reaction after middle cerebral artery occlusion in rat brain. J. Comp. Neurol. 327, 123-132.

Mullen, R.J., Buck, C.R., Smith, A.M., 1992. NeuN, a neuronal specific nuclear protein in vertebrates. Development 116, 201-211.

Neumann, J., Sauerzweig, S., Ronicke, R., Gunzer, F., Dinkel, K., Ullrich, O., Gunzer M., Reymann, K.G., 2008. Microglia cells protect neurons by direct engulfment of invading neutrophil granulocytes: a new mechanism of CNS immune privilege. J. Neurosci. 28, 5965-5975.

Paxinos, G., Watson, C., 2007. The rat brain in stereotaxic coordinates, 6th Edition. Academic Press, New York, pp. 456.

Ransohoff, R.M., Perry, V.H., 2009. Microglial physiology: unique stimuli, specialized responses. Annu. Rev. Immunol. 27, 119-145.

Robinson, A.P., White, T.M., Mason, D.W., 1986. Macrophage heterogeneity in the rat as delineated by two monoclonal antibodies MRC OX-41 and MRC OX-42, the latter recognizing complement receptor type 3. Immunology 57, 239-247.

Sarnowska, A., Braun, H., Sauerzweig, S., Reymann, K.G., 2009. The neuroprotective effect of bone marrow stem cells is not dependent on direct cell contact with hypoxic injured tissue. Exp. Neurol. 215, 317-327.

Schnell, L., Fearn, S., Klassen, H., Schwab, M.E., Perry, V.H., 1999. Acute inflammatory responses to mechanical lesions in the CNS: differences between brain and spinal cord. Eur. J. Neurosci. 11, 3648-3658.

Schroeter, M., Jander, S., Witte, O.W., Stoll, G., 1994. Local immune responses in the rat cerebral cortex after middle cerebral artery occlusion. J. Neuroimmunol. 55 195-203.

Schwarting, S., Litwak, S., Hao, W., Bahr, M., Weise, J., Neumann, H., 2008. Hematopoietic stem cells reduce postischemic inflammation and ameliorate ischemic brain injury. Stroke 39, 2867-2875.

Sobani, Z.A., Quadri, S.A., Enam, S.A., 2010. Stem cells for spinal cord regeneration: current status. Surg. Neurol. Int. 1, 93.

Souza-Rodrigues, R.D., Lima, R.R., Guimaraes-Silva, J., Costa, A.M., Dos Santos, C.D. Picanço-Diniz, C.W., Gomes-Leal, W., 2008. Inflammatory response and white matter damage after microinjections of endothelin-1 into the rat striatum. Brain Res. 1200C, 78-88.

Sughrue, M.E., Mocco, J., Komotar, R.J., Mehra, A., D’Ambrosio, A.L., Grobelny, B.T. Penn, D.L., Connolly Jr., E.S., 2006. An improved test of neurological dysfunction following transient focal cerebral ischemia in rats. J Neurosci Methods 151 , 83-89.

Takahashi, K., Yasuhara, T., Shingo, T., Muraoka, K., Kameda, M., Takeuchi, A., Yano, A., Kurozumi, K., Agari, T., Miyoshi, Y., Kinugasa, K., Date, I., 2008. Embryonic neural stem cells transplanted in middle cerebral artery occlusion model of rats demonstrated potent therapeutic effects, compared to adult neural stem cells. Brain Res. 1234, 172-182.

Thored, P., Heldmann, U., Gomes-Leal, W., Gisler, R., Darsalia, V., Taneera, J. Nygren, J.M., Jacobsen, S.E., Ekdahl, C.T., Kokaia, Z., Lindvall, O., 2009. Long term accumulation of microglia with proneurogenic phenotype concomitant with persistent neurogenesis in adult subventricular zone after stroke. Glia 57 835-849.

Tuttolomondo, A., Di Raimondo, D., di Sciacca, R., Pinto, A., Licata, G., 2008. Inflammatory cytokines in acute ischemic stroke. Curr. Pharm. Des. 14, 3574-3589.

Walton, N.M., Sutter, B.M., Laywell, E.D., Levkoff, L.H., Kearns, S.M., Marshall 2nd, G.P., Scheffler, B., Steindler, D.A., 2006. Microglia instruct subventricular zone neurogenesis. Glia 54, 815-825.

Weissman, I.L., Anderson, D.J., Gage, F., 2001. Stem and progenitor cells: origins phenotypes, lineage commitments, and transdifferentiations. Annu. Rev. Cell Dev. Biol. 17, 387-403.

Woodruff, T.M., Thundyil, J., Tang, S.C., Sobey, C.G., Taylor, S.M., Arumugam, T.V. 2011. Pathophysiology, treatment, and animal and cellular models of human ischemic stroke. Mol. Neurodegener. 6, 11.

Yang, B., Strong, R., Sharma, S., Brenneman, M., Mallikarjunarao, K., Xi, X., Grotta, J.C., Aronowski, J., Savitz, S.I., 2011. Therapeutic time window and dose response of autologous bone marrow mononuclear cells for ischemic stroke. J. Neurosci. Res. $89,833-839$.

Yong, V.W., Wells, J., Giuliani, F., Casha, S., Power, C., Metz, L.M., 2004. The promise of minocycline in neurology. Lancet Neurol. 3, 744-751.

Yoo, S.W., Kim, S.S., Lee, S.Y., Lee, H.S., Kim, H.S., Lee, Y.D., Suh-Kim, H., 2008. Mesenchymal stem cells promote proliferation of endogenous neural stem cells and survival of newborn cells in a rat stroke model. Exp. Mol. Med. 40, 387-397.

Yrjanheikki, J., Tikka, T., Keinanen, R., Goldsteins, G., Chan, P.H., Koistinaho, J., 1999. A tetracycline derivative, minocycline, reduces inflammation and protects against focal cerebral ischemia with a wide therapeutic window. Proc. Natl. Acad. Sci. U. S. A. 96, 13496-13500.

Zhang, Z.G., Chopp, M., 2009. Neurorestorative therapies for stroke: underlying mechanisms and translation to the clinic. Lancet Neurol. 8, 491-500. 